\title{
Suggestibility, Dissociation and Positive Schizotypy
}

\section{Sugestionabilidad, Disociación y Esquizotipia Positiva}

\author{
Emma Barkus \\ Institute of Psychiatry. London
}

\author{
John Stirling \\ Manchester Metropolitan University
}

\author{
John Cavill \\ Manchester Metropolitan University
}

\begin{abstract}
. 94 participants, drawn from a parent sample of 1206 individuals who had previously taken part in an assessment of the factor structure of the Oxford-Liverpool Inventory of Feelings and Experiences (O-LIFE), were designated into groups differentiated in terms of low, moderate or high levels of positive schizotypy. All also completed the dissociative experiences scale (DES) and the Inventory of Suggestibility (IS). Our findings suggest that higher reported levels of dissociative experiences and higher suggestibility both independently predict higher scores of positive schizotypy, although suggestibility appears to be a stronger predictor than dissociation.

Key words: dissociative experiences, suggestibility, positive schizotypy.

Resumen. Partimos de una muestra de 94 participantes, seleccionados de la muestra de referencia de 1206 personas que ya habían participado en un estudio que valoraba la estructura factorial del Oxford-Liverpool Inventory of Feelings and Experiences (O-LIFE). Estas 94 personas fueron asignadas en grupos diferenciados en términos de bajo, moderado o altos niveles de esquizotipia positiva. Todos completaron también la Escala de Experiencias Disociativas (DES) y el Inventario de Sugestionabilidad (IOS). Nuestros resultados sugieren que el aumento de los niveles informados de las experiencias disociativas y mayor sugestionabilidad, ambos, de forma independiente, predicen puntuaciones más altas de la esquizotipia positiva, pero la sugestión parece ser un predictor más potente que la disociación.

Palabras clave: experiencias disociativas, sugestionabilidad, esquizotipia positiva.
\end{abstract}

\section{Introduction}

An association between high levels of positive schizotypy (PS) and the tendency to lapse into dissociative states can now be considered a robust finding (Giesbrecht et al., 2008). The former is characterised by unusual experiences, perceptual disturbances, and hallucinatory proneness; and the latter by a range of experiences varying from occasional absentmindedness to impaired reality monitoring. One explanation for this synergy is that high scores on both are a consequence of childhood trauma (Brenner, 2001). Such experiences have been related to schizotypal symptoms (Berenbaum, Valera and

La correspondencia sobre este artículo puede dirigirse a John Stirling a través del correo electrónico: j.stirling@mmи.ac.uk
Kerns, 2003), and in the development of dissociative symptoms in those with schizophrenia (Holowka et al., 2003), although research by Irwin (2001) and Giesbrecht et al (2007) has not supported this link.

An alternative view is that both PS and dissociation are either elements of one undifferentiated dimension; 'openness to anomalous experiences' has been mooted (Wilson and Barber, 1993) although the evidence is again equivocal (Watson, 2001); or linked by the mediating construct of 'suggestibility', although questions remain about how to characterize and measure this. The Gudjonsson scale (Gudjonsson, 1984) emphasizes interrogative aspects whilst other measures stress hypnotic suggestibility (Shor and Orne, 1962; Bowers, 1998). Moreover, these two aspects of suggestibility may be only weakly related (Register and Kihlstrom, 
1988). Both Wolfradt and Meyer $(1997,1998)$ and Merckelbach et al (2000) reported that interrogative suggestibility correlated strongly with dissociation in anxious patients and controls respectively, although Dienes et al (2009) recently failed to establish any discernable relationship between hypnotic suggestibility and dissociation. Gruzelier et al (2004) reported an association between hypnotic suggestibility and PS; and suggestible respondents appear more likely to report anomalous experiences when put in ambiguous situations (eg; van de Ven and Merckelbach, 2003; Terhune and Smith, 2006), especially if they also evince higher schizotypy scores (Cella et al., 2007). Overall, these results suggest that further examination of the inter-relationships between suggestibility, dissociation and schizotypy would be worthwhile.

The data on which the present study is based derive from a larger investigation of correlates of schizotypy (Barkus, 2005); the protocol of which dictated that respondents be 'grouped' a priori in terms of high, moderate or low levels of PS. All additionally completed the DES and a self-report measure of suggestibility (along with a series of other measures not specifically relevant to this report). Our primary hypothesis was that PS would be associated with higher levels of both dissociation and suggestibility. Further multivariate procedures would permit identification of the best predictor(s) of PS.

\section{Method}

\section{Participants}

1206 respondents took part in an 'intranet-based' survey of the factor-structure of schizotypy using the Oxford-Liverpool Inventory of Feelings and Experiences (O-LIFE: Mason, Claridge and Jackson, 1995) and the Launay-Slade Hallucination Scale (LSHS: Launay and Slade, 1981), conducted within the two universities in Manchester, UK. (Barkus, 2005). The O-LIFE assesses four aspects of schizotypy: Unusual Experiences, Cognitive Disorganisation, Introvertive Anhedonia and Impulsive Nonconformity. The LSHS measures susceptibility to experiencing hallucinatory-like phenomena. PS group membership was determined on the basis of scores on both the unusual experiences scale (from the O-LIFE) and the LSHS: The high and a low PS groups recorded scores at least $1 \mathrm{sd}$ above/below the mean on the unusual experiences scale, and at least $0.5 \mathrm{sd}$ above/below the mean of the LSHS respectively. A moderate PS group was recruited from individuals whose scores were within $0.5 \mathrm{sd}$ of the mean on both measures. 432/1206 respondents were excluded either by non-qualification (or by prior indication that they did not wish to participate in this element of the study). The 3 PS groups were recruited from the remainder as independent 'opportunity samples' to provide an overall study sample size of $100+$ participants (suitably powered to detect significant differences on our soft-signs measures). They did not differ significantly in terms of age, sex ratio, or handedness. (See table 1).

Table 1. Three groups of respondents differentiated in terms of positive schizotypy (PS)

\footnotetext{
- High PS Group ( $\mathrm{N}=35)$

- Male: 16/ Female: 19

- Age: Mean: 21.71 (sd=3.85) (Range 18 years -38 years)

- Moderate PS Group (N=32)

- Male: 14/ Female: 18

- Age: Mean 22.84 (sd=7.00) (Range 18 years - 49 years)

- Low PS Group ( $\mathrm{n}=27)$

- Male: 8/ Female 19

- Age: Mean: 24.42 (sd=9.73) (Range 19 years -62 years)
}

\section{Instruments}

'Dissociation' was measured with the Dissociative Experiences Scale (DES: Bernstein and Putnam 1986, 1993) which comprises 28 'experiences' to be rated according to the frequency or extent to which each applies. It provides a total (DES:tot) and 3 subscale scores: dissociative amnesia (DES:da), depersonalization-derealisation (DES:dd) and absorption/ imaginary involvement (DES:aii). DES:tot is reported by the authors to have a test-retest reliability of 0.93 and the three subscales reliability coefficients of $0.95,0.89$ and 0.82 respectively.

Suggestibility was assessed using the Inventory of Suggestibility (IoS; González-Ordi and MiguelTobal, 1999); the original measure (22 items requiring a 5-point Likert scale response) being translated from Spanish. The IoS was developed to assess 
aspects of suggestibility extending beyond hypnotic and interrogative components.. to include gullibility and acquiescence. In their initial analyses, the authors reported that it comprises four sub-scales; fantasy proneness, absorption, emotional suggestibility and influence of others, each accounting for about $12 \%$ of overall variance. As an English version had not previously been used, we piloted it on an opportunity sample of students and staff $(\mathrm{n}=230)$ drawn from the two Manchester universities. This version generated an alpha reliability coefficient of 0.82 . However, one item relating to becoming absorbed in TV programmes or films overlapped with item 17 on the DES:aii sub-scale and was removed. PCA of the remaining 21 items indicated one substantive factor $(>24 \%$ of overall variance) which we characterized by considering only unique loadings of at least 0.5 . The resulting sub-scale (alpha $=0.81)$ comprised 8 items all related to the direct or indirect 'influence of others' (IoS:inf). For example; Peoples' opinions are important to me; I believe in the things others say. Thus, for the purposes of this report, our two indices of suggestibility were IoS:tot and IoS:inf.

\section{Procedure}

Respondents completed the DES and IoS anonymously approximately 5 weeks after completing the O-LIFE and LSHS, alongside other measures relating to the parent study.

\section{Data analysis}

Comparisons between PS groups were made using ANOVA, ANCOVA and tests of trend. Multivariate procedures permitted examination of predictors of PS group membership. DES total and sub-scales were positively skewed and required appropriate transformation.

\section{Results}

94 respondents $(35,32$ and 27 in the high, moderate and low PS groups respectively) generated a full data-set relevant to this investigation. Comparison of mean PS scores with overall means from the parent study confirmed the representative nature of our groups.

One way ANOVAs indicated that the 3-level group factor accounted for a significant amount of the variance for both total and sub-scale scores (ranging from $7 \%$ for DES:da to $36 \%$ for IoS:tot: see table 2). This table also shows consistent and highly significant linear trends of increased dissociation and suggestibility across PS groups. ANCOVA in which DES:tot was compared between groups with IoS:tot as covariate indicated that inclusion of suggestibility rendered the difference between groups in DES:tot non-significant, $[\mathrm{F}(2,90)=2.24$, $\mathrm{p}=0.114]$ whereas the inclusion of DES:tot as a covariate left a highly significant difference between PS groups on IoS: tot [ F $(2,90)=14.81, p=0.0005]$.

Two discriminant function analyses were then performed: In the first just DES:tot and IoS:tot were considered in relation to the principal function which, in this case, accounted for $97.8 \%$ of variance. IoS:tot was, by some margin the stronger correlate (largest absolute coefficient for IoS: tot $=0.953 \mathrm{com}$ pared with 0.595 for DES:tot). A second analysis using the three DES and single IoS sub-scales again showed the effectiveness of suggestibility as a predictor of PS group membership. In this analysis, IoS:inf gave the primary contribution to the principal function (largest absolute coefficient $=0.932$ ) with some additional refinement from DES:aii (largest absolute correlation coefficient $=0.646$ ).

Finally, regression was employed to establish predictors of high and low PS group membership. When total scores were considered, IoS:tot was the sole predictor (Wald $=17.82, \mathrm{p}<0.001$ ). Repeating this analysis with the three DES and single IoS subscales as independent variables, IoS:inf was the best predictor at step one, joined at step two by DES:aii to give final Wald values of $7.85(\mathrm{p}=0.005)$ and 4.63 $(\mathrm{p}=0.31)$ respectively.

\section{Discussion}

We have found a linear trend of increased dissociative experiences and suggestibility in individuals 
Table 2. Mean suggestibility and dissociation scores for the three positive schizotypy (PS) groups

\begin{tabular}{|c|c|c|c|c|c|c|}
\hline PS group & High & Mod & Low & sd & $\mathrm{F}^{\$}$ & $\begin{array}{c}\text { \%var } \\
\text { explained }\end{array}$ \\
\hline $\mathrm{N}$ & 35 & 32 & 27 & & & \\
\hline IoS:inf & 11.54 & 10.06 & 7.96 & 3.44 & $9.8^{* * *}$ & 17.3 \\
\hline IoS:total & 51.20 & 39.37 & 33.85 & 12.17 & $25.7^{* * *}$ & 33.5 \\
\hline DES:da & 7.41 & 5.21 & 3.14 & $6.89 *$ & $3.4^{*}$ & 6.1 \\
\hline DES:aii & 26.00 & 18.54 & 9.37 & $14.86^{*}$ & $13.6^{* * *}$ & 21.0 \\
\hline DES:dd & 4.38 & 1.12 & 0.80 & $5.45^{*}$ & $6.6^{* *}$ & 10.4 \\
\hline DES:total & 16.55 & 11.66 & 6.68 & $9.69 *$ & $10.7^{* * *}$ & 17.5 \\
\hline \multicolumn{7}{|c|}{ 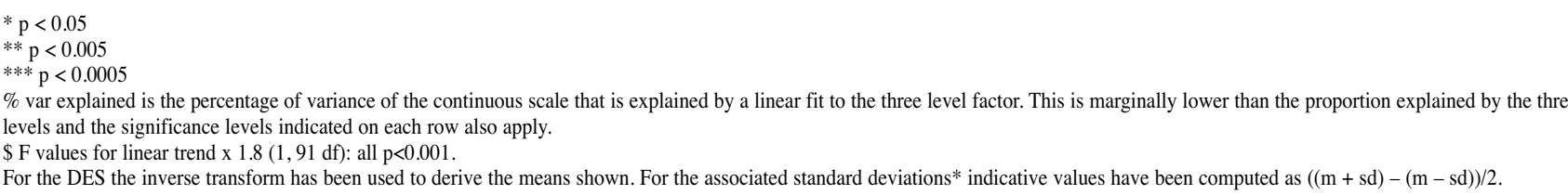 } \\
\hline
\end{tabular}

categorised in terms of low, moderate or high PS. ANCOVA, discriminant function analyses, and regression analyses all suggest that although both are associated with higher scores of PS, some, at least, of the PS-dissociation link is likely mediated by suggestibility, and perhaps in particular, by 'openness to the influence of others' (IoS:inf).

Intriguing though these findings appear, it is important to be able to rule out the possibility that they may be a consequence of the similarity between test items from which the two scales are derived. After all, both scales address the issues of absorption, dream/reality boundaries and intensity of memory for past events. However, whereas most of the IoS items address relatively straightforward if subjective experiences such as 'I am easily influenced by other peoples' moods', and 'I am a suggestible person', most DES items additionally involve some aspect of 'reality slippage': for example, '... the experience of looking in a mirror and not recognising myself...' [item 11] or '...feeling that other people, objects and the world around (me) are not real' [item 12]. This is hardly surprising since the DES was originally constructed for clinical applications. However, it might explain the highly positively skewed distribution of DES scores routinely reported when dissociation is assessed in non-clinical samples (ie; a generally low endorsement rate), and the efforts of certain researchers to modify the for- mat (or scoring system) of the DES to make it more suitable for non-clinical respondents (eg; Wright and Loftus, 1999). Conversely, the IoS:inf sub-scale comprises items relating to acquiescence to the views, thoughts or feelings of others, and has little or no overlap with any DES items. IoS:inf was the best independent predictor of PS group membership and, in combination with the DES:aii sub-scale, correctly classified $>80 \%$ of respondents (actually 29 of 35 in the high PS group). These findings suggest that both certain dissociative tendencies and certain aspects of suggestibility predict level of PS, but that this effect cannot simply be attributed to 'overlap' between test items in the two scales. One interpretation of these observations is that a high level of positive schizotypy is a psychometric proxy for openness to [anomalous] experiences which, in turn, are more likely to be reported by 'suggestible' individuals evincing dissociative tendencies in the realm of day-dreaming and absorption.

In interpreting our findings, we should sound several notes of caution. Firstly, our little-used selfreport measure of suggestibility merits further scrutiny, particularly in relation to other more widely used suggestibility measures. Secondly, the obligate grouping of individuals into three bands of PS limited our choice of statistical procedures, and there would be merit in seeking to recruit a larger 'continuously-distributed' sample of respondents to 
optimise these. Finally, alternative means of scoring the DES are, we believe, urgently required in order to improve its psychometric properties for use in non-clinical samples.

In conclusion our findings suggest that a tendency to readily acquiesce to the thoughts, feelings and emotions of others (reflected by the IoS:inf subscale) combines with the DES:aii sub-scale to predict greater openness to the reporting of anomalous experiences; an interactive effect that appears more marked in individuals with pre-existing higher levels of positive schizotypy.

\section{References}

Barkus, E. (2005). The Psychobiological Correlates of Schizotypy in a Student Sample; PhD dissertation, Manchester Metropolitan University, UK.

Berenbaum, H., Valera E.M. and Kerns J.G. (2003). Psychological trauma and schizotypal symptoms. Schizophrenia Bulletin 29, 143-152.

Bernstein, E.M. and Putnam, F.W. (1986). Development, reliability, and validity of a dissociation scale. The Journal of Nervous and Mental Disease 174, 727-735.

Bernstein, E.M. and Putnam, F.W. (1993). An update on the Dissociative Experiences Scale. Dissociation 6, 16-27.

Bernstein, D.P., Fink, L., Handelsman, L., Foote, J., Lovejoy, M., Wenzel, K., Sapareto, and E., Ruggiero, J. (1994). Initial reliability and validity of a new retrospective measure of child abuse and neglect. American Journal of Psychiatry 151, 1132-1136.

Bowers, K.S. (1998). Waterloo-Stanford Group Scale of Hypnotic Susceptibility, Form C: Manual and response booklet. International Journal of Clinical and Experimental Hypnosis 46, 250-268.

Bradbury, D.A., Stirling, J., Cavill, J. and Parker, A. (2009). Psychosis-like experiences in the general population: An exploratory factor analysis. Personality and Individual Differences 46, 729734.

Brenner, I. (2001). Dissociation of trauma. Guilford, CT: International UP.
Carlson, E.B., Putnam, F.W., Ross, C. Anderson, G., Clark, P. and Torem, M. (1991). A factor analysis of the Dissociative Experiences Scale using multicenter data. In: B.G. Braun and E.B. Carlson, Editors, Proceedings of the Eighth International Confe-rence on Multiple Personality/Dissociative Sta-tes; Chicago, IL: Rush.

Cella, M., Taylor, K. and Reed, P. (2007). Violation of expectancies produces more false positive reports in a word detection task in people scoring high in unusual experiences scale. Personality and Individual Differences 43, 59-70.

Dubester, K.A. and Braun, B.G. (1995). Psychometric properties of the Dissociative Experiences Scale. Journal of Nervous and Mental Disease 183, 231235.

Giesbrecht, T., Merckelbach, H., Kater, M. and Sluis, A.F. (2007). Why dissociation and schizotypy overlap - The joint influence of fantasy proneness, cognitive failures, and childhood trauma. The Journal of Nervous and Mental Disease $195,812-818$

Giesbrecht, T., Lynn, S.J., Lilienfeld, S.O. and Merckelbach, H. (2008). Cognitive processes in dissociation: An analysis of core theoretical assumptions. Psychological Bulletin 134, 617-647.

Giesbrecht, T. and Merckelbach, H. (2008). The complex overlap between dissociation and schizotypy. In A Moskowitz, I Schäfer \& M Dorahy (Eds.), Dissociation and psychosis: Multiple perspectives on a complex relationship (pp 79-89). New York: John Wiley and Sons.

González-Ordi, H.Y. and Miguel-Tobal, J.J. (1999). Characteristics of suggestibility and its relationship with other psychological variables. Annals of Psychology 15, 57-75.

Gudjonsson, G.H. (1984). A new scale of interrogative suggestibility, Personality and Individual Differences 5, 303-314.

Holowka, D.W., King, S., Saheb, D., Pukall, M. and Brunet, A. (2003). Childhood abuse and dissociative symptoms in adult schizophrenia. Schizophrenia Research 60, 87-90.

Irwin, H.J. (2001). The relationship between dissociative tendencies and schizotypy: An artifact of childhood trauma? Journal of Clinical Psychology 57, 331-342. 
Launay, G. and Slade, P.D. (1981). The measurement of hallucinatory predisposition in male and female prisoners. Personality and Individual Differences 2, 221-234.

Mason, O., Claridge, G. and Jackson, M. (1995). New scales for the assessment of schizotypy. Personality and Individual Differences 18, 7-13.

Merckelbach, H., Muris, P., Horselenberg, H. and Stougie, S. (2000). Dissociation, reality monitoring, and response bias. Personality and Individual Differences 28, 49-58.

Register, P. A. and Kihlstrom, J.F. (1988). Hypnosis and interrogative suggestibility. Personality and Individual Differences 9, 549-558.

Shor, R. and Orne, E. (1962). Harvard group scale of hypnotic susceptibility, form A. Palo Alto, CA: Consulting Psychologists Press.

Terhune, D.B. and Smith, M.D. (2006). The Induction of Anomalous Experiences in a MirrorGazing Facility: Suggestion, Cognitive Perceptual Personality Traits and Phenomenological State Effects. The Journal of Nervous and Mental Disease 194, 415-421

Van de Ven, V. and Merckelbach, H. (2003). The role of schizotypy, mental imagery, and fantasy proneness in hallucinatory reports of undergraduate students. Personality and Individual Differences 35, 889-896.

Watson, D. (2001). Dissociations of the night: individual differences in sleep-related experiences and their relation to dissociation and schizotypy. Journal of Abnormal Psychology 110, 526535.

Wilson, S.C. and Barber, T.X. (1983). The fantasyprone personality: Implications for understanding imagery, hypnosis, and parapsychological phenomena. In Imagery: Current Theory, Research, and Application; AA Sheikh (ed.) pp 340-390, Wiley: New York.

Wolfradt, U. (1997). Dissociative experiences, trait anxiety and paranormal beliefs. Personality and Individual Differences 23, 15-19.

Wolfradt, U. and Meyer, T. (1998). Interrogative suggestibility, anxiety and dissociation among anxious patients and normal controls. Personality and Individual Differences 25, 425-432.

Wright, D.B. and Loftus, E.F. (1999). Measuring dissociation: comparison of alternative forms of the dissociative experiences scale. The American journal of psychology, 112, 497-519.

Received article: 28/01/2010

Received review: 25/02/2010

Accepted: 02/03/2010 